\title{
Biopori: Alternatif Pencegahan Banjir Melalui Pemberdayaan Masyarakat Pondok Pesantren
}

\author{
Wiwik Kusumawati ${ }^{*}$, Fitri Arofiati ${ }^{2}$ \\ ${ }^{1}$ Fakultas Kedokteran dan Ilmu Kesehatan Universitas Muhammadiyah Yogyakarta \\ ${ }^{2}$ Magister Keperawatan Universitas Muhammadiyah Yogyakarta, \\ Jalan Brawijaya Tamantirto Kasihan Bantul 55183, Telp. 274387656, 08164224386 \\ Email: Wiwik@umy.ac.id \\ DOl: $10.18196 / p p m .32 .222$
}

\begin{abstract}
Abstrak
Indonesia merupakan salah satu negara yang tergolong rawan terhadap kejadian bencana alam. Salah satu bencana alam yang sering terjadi di Indonesia adalah banjir. Curah hujan yang tinggi pada bulan-bulan tertentu menyebabkan banjir. Banjir menjadi salah satu bencana alam yang harus diwaspadai di beberapa wilayah di Indonesia. Daerah Wonokromo, Pleret, Bantul, Yogyakarta yang dikenal sebagai desa santri merupakan salah satu wilayah di Yogyakarta yang mengalami banjir hampir setiap tahunnya. Kondisi alam yang sudah rusak dan kehilangan lahan serapan membuat bencana banjir menjadi semakin mengancam, terutama pada wilayah dengan dataran yang lebih rendah. Untuk mengantisipasi bencana banjir, perlu adanya upaya untuk menyelesaikan permasalahan yang menyebabkan munculnya banjir pada musim-musim tertentu. Salah satunya dengan cara meyediakan lubang serapan (biopori) agar air tidak mengenang dan meluap di wilayah pemukiman saat cuaca ekstrem dengan melibatkan masyarakat, terutama remaja sebagai agen perubahan. Kegiatan pengabdian masyarakat ini merupakan pemberdayaan masyarakat pondok pesantern di wilayah Wonokromo, Pleret, Bantul dalam pencegahan bencana banjir melalui sosialisasi penanggulangan banjir terkait modifikasi lingkungan dengan metode biopori. Warga pesantren akan dibekali informasi yang secara umum terkait biopori dan cara pembuatan biopori secara mandiri. Warga pesantren juga didampingi dalam penerapan pembuatan biopori di lingkungan pemukiman dan pemasangannya. Kegiatan dilakukan pada tanggal 16 Februari 2020 dengan melibatkan 50 orang warga porndok pesantren $(5$ pondok pesantren). Hasil pengabdian masyarakat adalah terpasangnya 70 biopori yang dibagi dalam 5 zona berdasarkan wilayah pondok pesantren. Masyarakat menyampaikan rasa aman dalam menghadapi musim penghujan. Masyarakat membuat biopori sejumlah lima belas dengan pendampingan. Biopori menjadi salah satu alternatif pencegahan banjir yang mampu memberdayakan masyarakat dan meningkatkan rasa aman.
\end{abstract}

Kata Kunci: Banjir, Biopori, Kesiapsiagaan, Pemberdayaan masyarakat

\section{Pendahuluan}

Indonesia merupakan salah satu negara yang tergolong rawan terhadap kejadian bencana alam. Kondisi tersebut disebabkan Indonesia memiliki tiga pola iklim dasar: monsunal, khatulistiwa, dan sistem iklim lokal yang menyebabkan perbedaan pola curah hujan di beberapa wilayah. Kondisi tersebut membuat pemanasan global dan pengaruh iklim seperti kenaikan suhu dan permukaan air laut pada wilayah Indonesia yang berada di garis khatulistiwa. Kondisi ini menyebabkan tingginya peristiwa bencana alam (BNBP, 2017). Salah satu bencana alam yang sering terjadi di Indonesia adalah banjir. Curah hujan yang tinggi pada bulan-bulan tertentu menyebabkan banjir. Banjir menjadi salah satu bencana alam yang harus diwaspadai di beberapa wilayah di Indonesia. Yogyakarta menjadi salah satu wilayah yang terdampak bencana banjir.

Daerah Pleret, Bantul merupakan salah satu wilayah di Yogyakarta yang mengalami banjir hampir setiap tahunnya. Curah hujan yang tinggi dan dataran yang lebih rendah membuat wilayah ini menjadi wilayah yang sering mengalami musibah banjir, Pada tahun 2017, dari surat kabar Kedaulatan Rakyat pada edisi tanggal 28 November 2017 diberitakan bahwa wilayah Wonokromo, Pleret, Bantul menjadi salah satu wilayah yang terendam banjir disebabkan adanya hujan lebat yang mengguyur Daerah Istimewa Yogyakarta. Berita yang sama juga terjadi pada tahun 2019 yang dikutip dari Sindonews Jateng \& DIY edisi 17 Maret 2019, yang menginformasikan bahwa wilayah Dusun Jejeran, Wonokromo, Pleret, Bantul terisolasi karena terendam banjir luapan Sungai Belik yang diterpa hujan berhari-hari. Masyarakat di wilayah 
tersebut mengatakan masih minim informasi terkait bencana banjir sehingga merasa kebingungan untuk menanggulangi permasalahan banjir yang ada. Masyarakat juga mengeluhkan saat terjadi banjir warga lebih cendrung langsung mengungsi. Masyarakat tidak memiliki kesadaran atau insiatif untuk memodifikasi alam sebagai pencegahan air yang masuk ke dalam rumah.

Kondisi alam yang sudah rusak dan kehilangan lahan serapan membuat bencana banjir menjadi semakin mengancam, terutama di wilayah dengan dataran yang lebih rendah. Kehilangan dan kerusakan yang diakibatkan oleh banjir mengagnggu kehidupan dan penghidupan masyarakat sehingga perlu adanya penanggulangan untuk mengatasi permasalahan banjir. Bencana banjir juga memberikan dampak yang buruk pada psikologis dan kesehatan orang-orang di wilayah yang terdampak. Demam Berdarah, diare, penyakit kulit, dan beberapa permasalahan kesehatan lainnya sering menjadi permasalahan pendamping saat terjadinya bencana banjir. Kondisi tersebut menambah daftar penderitaan dan kesengsaraan dalam menghadapi bencana banjir.

Dalam mengantisipasi bencana banjir, perlu adanya upaya menyelesaikan permasalahan yang menyebabkan munculnya banjir pada musim-musim tertentu. Salah satunya adalah dengan meyediakan lubang serapan agar air tidak mengenang dan meluap di wilayah pemukiman saat cuaca ekstrem. Lubang serapan tersebut dikenal dengan nama biopori. Biopori merupakan lubang serapan organik yang berfungsi sebagai tempat berlalunya air ke dalam tanah (Ichsan \& Hulalata, 2018). Pada lubang tersebut akan diisi oleh sampah-sampah organic dan membentuk aktivitas organisme di dalamnya sehingga menimbulkan daya resap air yang lebih tinggi. Lubang serapan ini diharapkan dapat menjadi salah satu solusi dalam menanggulangi banjir di wilayah pemukiman dan menurunkan angka kesakitan yang diakibatkan oleh bencana banjir. Pembuatan biopori menjadi salah satu strategi yang dapat diterapkan pada wilayah yang rawan dengan bencana banjir. Peran serta masyarakat sangat penting dalam pembuatan serta perawatan lubang biopori ini. Selain adanya modifikasi lingkungan dengan pembuatan biopori, strategi selanjutnya dalam penanggulangan bencana banjir adalah kesiapsiagaan masyarakat dalam menghadapi bencana banjir.

Berdasarkan permasalahan yang ada, dibentuk sebuah kegiatan pengabdian masyarakat dengan tema optimalisasi warga pondok pesantren dalam pencegahan bencana banjir di wilayah Wonokromo, Pleret, Bantul.

\section{Metode Pelaksanaan}

1. Langkah Pelaksanaan Kegiatan

Langkah-langkah pelaksanaan kegiatan pengabdian kepada masyarakat sebagai berikut: 
PROSES

\section{TAHAP} PERIJINAN

Penyusunan proposal<smiles>[Li][V]</smiles>

Penyusunan surat kesediaan mitra

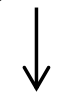

Penyusunan surat peminjaman ruangan/balai pertemuan

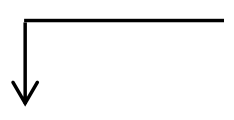

Edukasi bencana banjir<smiles>C=IC</smiles>

Melakukan pelatihan pembuatan biopori<smiles>C1CCC1</smiles>

Pengoptimalkan kader pondok pesantren<smiles>C=[V]</smiles>

Melakukan simulasi pembuatan lubang serapan biopori
LUARAN

Proposal

Surat kesediaan mitra

Surat peminjaman ruangan/balai pertemuan
INDIKATOR KETERCAPAIAN

Proposal tersusun

Surat kesediaan mitra disepakati

Surat peminjaman ruangan tersusun

\section{PELAKSANAAN DAN} PENDAMPINGAN
Mitra mengetahui bencana banjir

Mitra mampu membuat biopori

Meningkat kemampuan skill kader

Mitra mengetahui penanganan banjir
Memahami konsep bencana banjir dan penanganannya

Meningkatnya skill pembuatan biopori

Terbentuknya kader pondok pesantren

Meningkatnya kognitif mitra 
Post test

pengetahuan dan

skill<smiles>C=[V]</smiles>

Evaluasi kader

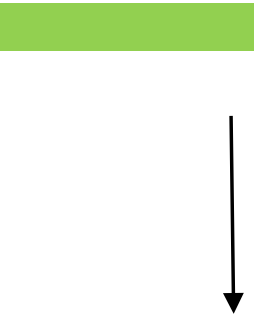

PUBLIKASI HASIL

Press release

media massa
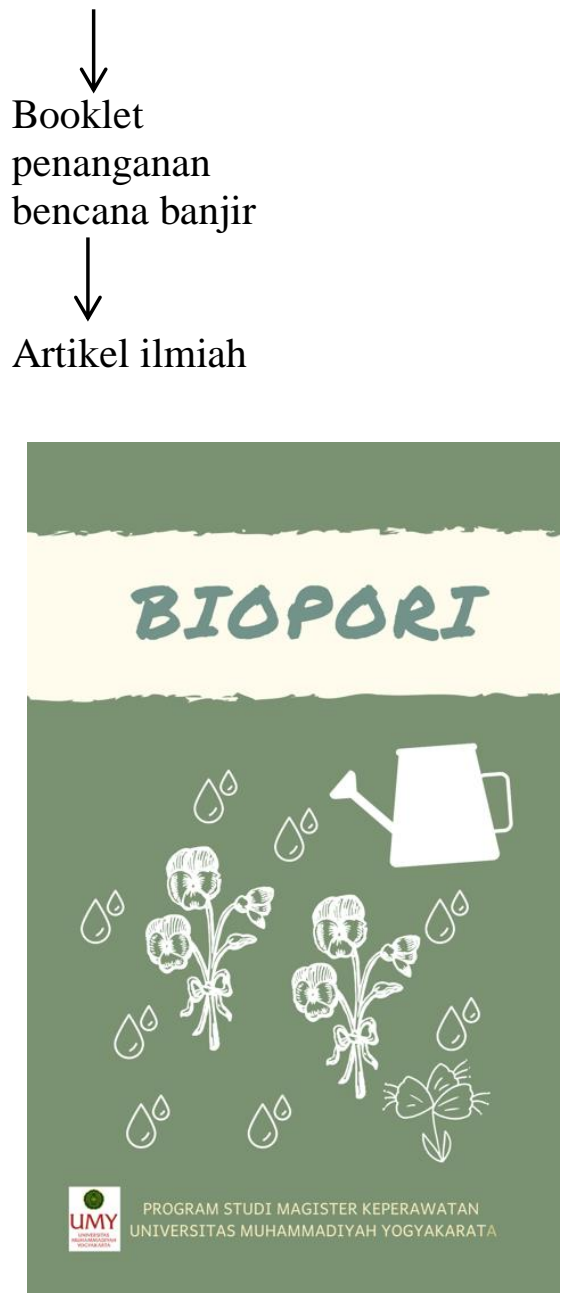

Booklet penanganan banjir dan biopori

Kader memahami materi yang disampaikan

Pembuatan konten berita

Artikel ilmiah

Hasil pengukuran

pengetahuan dan skill

bertambah

Kader dapat

melaksanakan kegiatan

secara mandiri

Dipublikasikan di media massa

Tersusunnya booklet tentang banjir dan biopori

\section{Desain Alat}

\section{Booklet Biopori}

Booklet disusun sebagai salah satu media pembelajaran bagi masyarakat pondok pesantren dengan menggunakan bahasa yang mudah dipahami. Isi booklet ini meliputi:

a. Pengertian biopori

b. Manfaat biopori

c. Konsep dasar pembuatan biopori

d. Peralatan dan bahan pembuatan biopori

e. Lubang peresapan biopori

f. Cara pembuatan

g. Lokasi pemasangan

h. Penggunaan biopori untuk pengomposan

i. Kompos

j. Durasi waktu pembuatan

k. Referensi

\section{Hasil dan Pembahasan}

1. Lokasi mitra

Lokasi pengabdian masyarakat ini berada di wilayah Dusun Wonokromo II, Wonokromo, Pleret, Bantul, Yogyakarta. Dusun ini terbagi atas 5 RT dan memiliki 5 pondok pesantren yang dikelola secara mandiri. Kelima pondok pesantren ini memiliki santri yang berasal dari latar belakang pendidikan dan budaya yang berbeda, tetapi sebagian besar berusia remaja. 


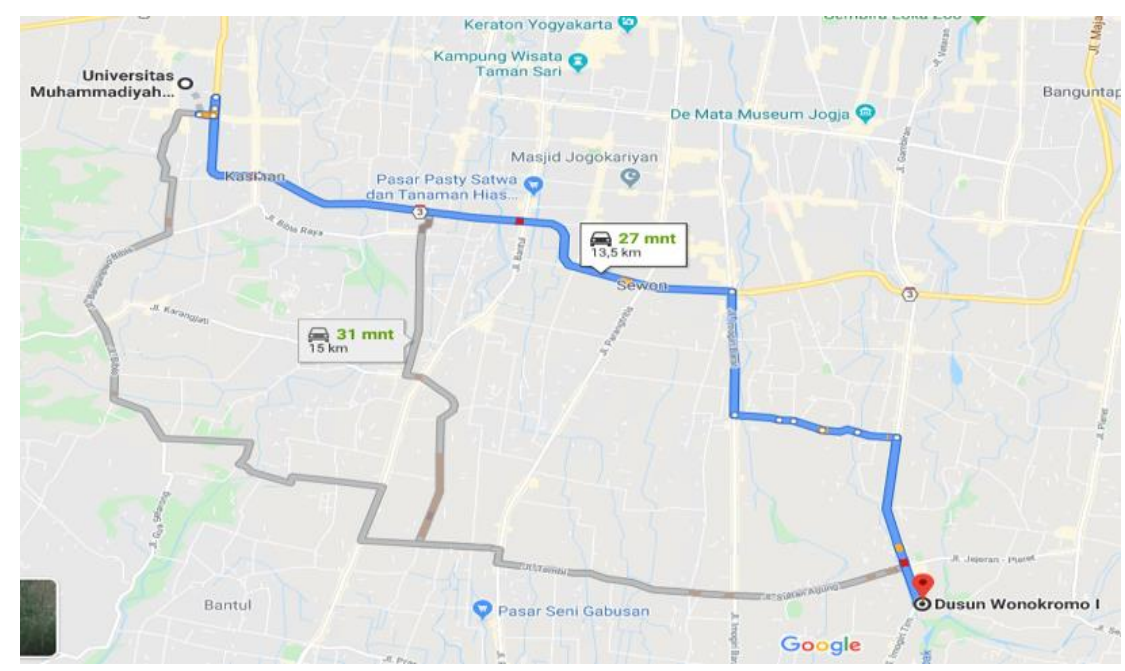

Gambar 1. Peta lokasi pengabdian masyarakat

Hasil pengabdian masyarakat ini menunjukkan antusiasme masyarakat pondok pesantren dalam melakukan upaya pencegahan banjir dan meningkatkan pemahaman tentang alternatif modifikasi lingkungan terhadap bahaya banjir dengan pembuatan dan pemasangan biopori. Masyarakat pondok pesantern mendapatkan dukungan dari pamong dusun dan warga lainnya dalam menjalankan peran dan fungsinya.

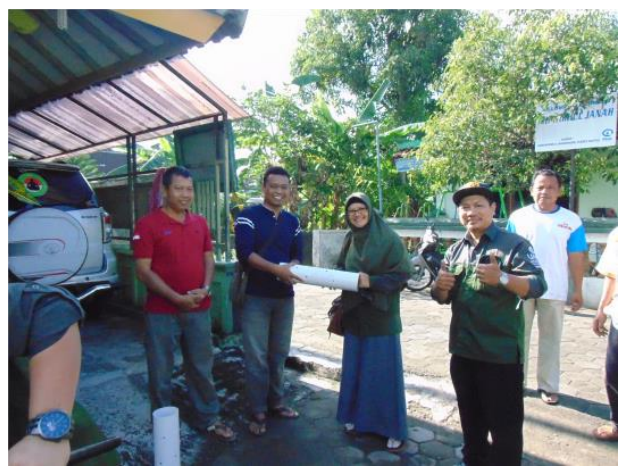

(a) Penyerahan alat biopori

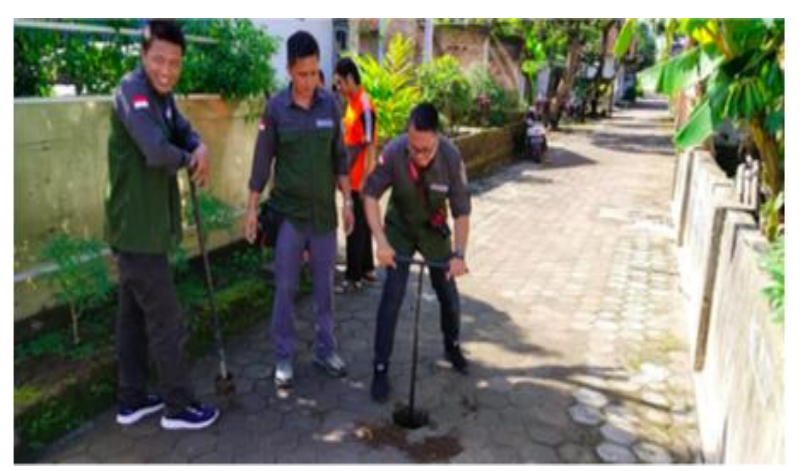

(b) Pelubangan Tanah

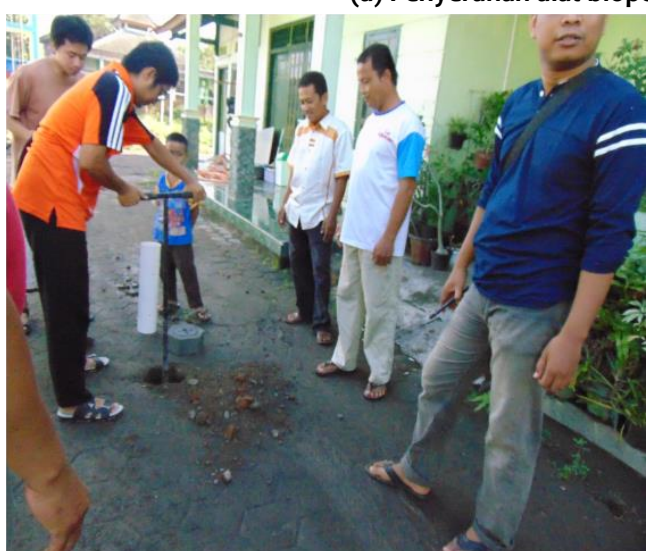

(a) Pelubang Tanah

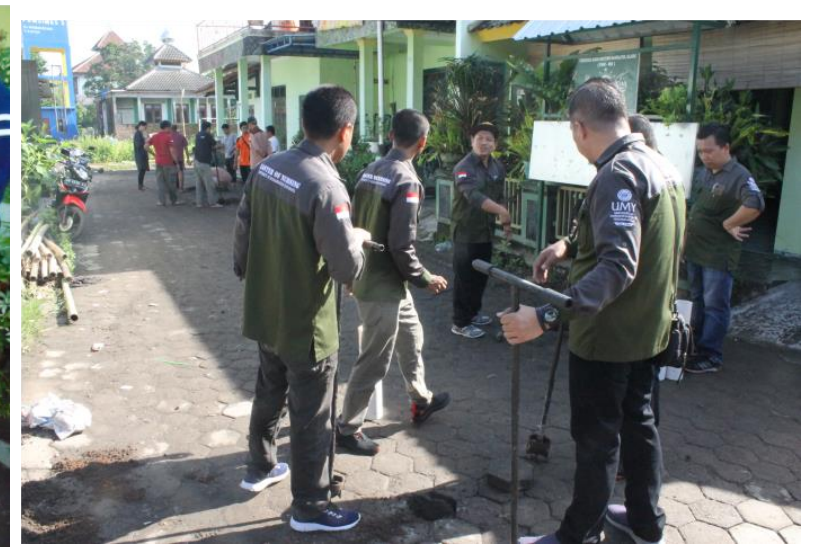

(b) Pelubangan Tanah

Gambar 2. (a,b,c,d) Proses Kegiatan

Kesadaran masyarakat dalam pencegahan banjir sangat dibutuhkan, terutama agar tidak menimbulkan korban material dan nonmaterial. 


\section{Kesimpulan}

Pemberdayaan masyarakat pondok pesantren dalam pembuatan dan pemasangan biopori sebagai upaya pencegahan banjir mampu meningkatkan rasa aman yang dirasakan, terutama dalam menghadapi musim penghujan.

\section{Ucapan Terima Kasih}

Kami mengucapkan terima kasih kepada Rektor Universitas Muhammadiyah Yogyakarta khususnya Kepala LP3M yang telah memberikan kesempatan dan pendanaan sehingga pengabdian masyarakat ini dapat terwujud. Ucapan terima kasih juga kami sampaikan kepada Kepala Dusun Wonokromo, Pleret, Bantul dan masyarakat pondok pesantren yang telah memberi izin dan berpartisipasi dalam pelaksanaan pengabdian masyarakat. Tidak lupa pula kami mengucapkan terima kasih kepada Ketua Program Studi Magister Keperawatan yang telah memberikan izin dan diskusi konten pengabdian masyarakat yang dilakukan.

\section{DAFTAR PUSTAKA}

Edo, (2019) Analisis Banjir dan Pemetaan Kawasan Terdampak Banjir di kelurahan Laweyan, Kota Surakata.

Findayani, A. (2015). Media Infromasi Pengembangan Ilmu dan Profesi Kegeografian. 13.

Fitriana, B. R. (2019). Hubungan Faktor Suhu Dengan Kasus Demam Berdarah Dengue (Dbd) Di Kecamatan Sawahan Surabaya. The Indonesian Journal of Public Health, 13(1), 85. https://doi.org/10.20473/ijph.v13i1.2018.85-97

Harahap, I., Herlina, N., Badrun, Y., \& Gesriantuti, N. (2017). Pembuatan Lubang Resapan Biopori Sebagai Alternatif Penanggulangan Banjir Di Kelurahan Maharatu Kecamatan Marpoyan Damai Pekanbaru. 1, 5.

Hariyanto, S. (2019). Pengaruh Metode Simulasi Bencana Banjir Terhadap Tingkat Kesiapsiagaan Mahasiswa Program Studi Ilmu Keperawatan Fik Unipdu Jombang. 7.

Husna, T. M. (2017). Faktor-Faktor Yang Berhubungan Dengan Kesiapsiagaan Tenaga Puskesmas Dalam Menghadapi Bencana Gempa Dan Tsunami Di Kota Padang Tahun 2017 [Diploma, Universitas Andalas]. http://scholar.unand.ac.id/28867/

Ichsan, I., \& Hulalata, Z. S. (2018). Analisa Penerapan Resapan Biopori Pada Kawasan Rawan Banjir Di Kecamatan Telaga Biru. Gorontalo Journal of Infrastructure and Science Engineering, 1(1), 33. https://doi.org/10.32662/gojise.v1i1.139

Rini, E. P. (2017). Tingkat Pemahaman Kesiapsiagaan Kepala Keluarga dalam Menghadapi Bencana Gempa Bumi di Dusun Potrobayan Desa Srihardono Kecamatan Pundong

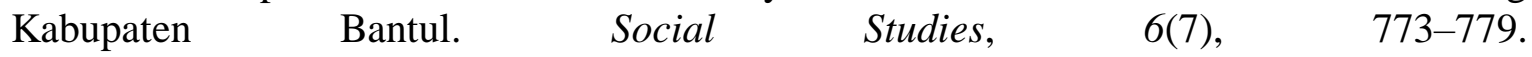
http://journal.student.uny.ac.id/ojs/index.php/social-studies/article/view/10268

Santoso, D. H. (2019). Penanggulangan Bencana Banjir Berdasarkan Tingkat Kerentanan dengan Metode Ecodrainage Pada Ekosistem Karst di Dukuh Tungu, Desa Girimulyo, Kecamatan Panggang, Kabupaten Gunungkidul, DIY. 9.

Sulistiowati, (2019). Pengabdian Untuk Mewujudkan Desa Pleret Sebagai Desa Sehat Sehingga Mampu Secara Mandiri Dan Berkelanjutan Mengatasi Permasalahan Demam Berdarah Dengue 